\title{
ASSESSMENT OF THE QUALITY OF OUTPATIENT PRESCRIPTIONS FROM VARIOUS CLINICAL SETTING IN A TERTIARY HOSPITAL, SAUDI ARABIA
}

\author{
SULTAN M. ALSHAHRANI* \\ Department of Clinical Pharmacy, College of Pharmacy, King Khalid University, Abha, Saudi Arabia. Email: Shahrani@kku.edu.sa
}

Received: 15 November 2018, Received and Accepted: 05 December 2018

\begin{abstract}
Objective: The quality of prescribing influences, to a large extent, the health outcomes of patients as errors made could result in adverse drug reactions. The aim of this study is to assess determine the quality of outpatient prescriptions in various clinical settings in Aseer region, Kingdom of Saudi Arabia.

Methods: An observational, cross-sectional descriptive study was carried out in various community pharmacies where the prescriptions received were analyzed for their quality.

Results: The prescriptions were checked for the completeness of the patients' biodata (name, age, sex, and hospital number), categories of drugs, prescribing by generic name, legibility of prescriber's writing, the name, and signature of the prescriber. Two hundred and fifty prescriptions were collected and used for analysis. A significant number of the prescriptions were written in illegible (26\%) handwriting. The name (15\%), age (48\%), and sex $(46 \%)$ of the patient were not mentioned in the majority of the prescriptions. Most of the prescriptions (94\%) failed to demonstrate the presence of address, height, and weight of the patient. Brand name of the drugs was mentioned in all the prescriptions, with only $17 \%$ of them having the generic name. The doctor's name, signature was present in $81 \%$ and $70 \%$ of the prescription, respectively.
\end{abstract}

Conclusion: Study shows that there is a need for improvement in the quality of prescription written by doctors. The adoption of a computer-aided prescribing system in an outpatient setting would go a long way in achieving this objective.

Keywords: Outpatient, Written prescription, Quality of prescription, Health outcomes.

(C) 2019 The Authors. Published by Innovare Academic Sciences Pvt Ltd. This is an open access article under the CC BY license (http://creativecommons. org/licenses/by/4. 0/) DOI: http://dx.doi.org/10.22159/ijap.2019.v11s5.T0021

\section{INTRODUCTION}

Prescriptions act as the core communicating medication plans from prescribers to pharmacists and finally, to patients [1]. Prescriptions can also be used as a measure of the quality of medical education, observance of the laws and regulations, and socio-cultural beliefs [2].

A good prescription is rational, evidence-based, clear, and complete and improves the treatment outcome of the patient. While prescribing without an appropriate indication, correct dose, frequency, route of administration, schedule or duration of treatment and duplicate therapeutic agents and medication of potential drug-drug interactions or adverse reactions are all forms of inappropriate prescribing [3].

The World Health Organization (WHO) estimates that worldwide, more than $50 \%$ of all medicines are prescribed, dispensed, or sold inappropriately, and about half of all patients fail to take their medicines correctly (WHO 2009). Lack of attention during prescription writing can lead to prescription errors which, in turn, can adversely affect patients' well-being. Thus, prescriptions are an important target area for improvement [4]. Prescription quality can be a direct predictor of the net outcome of a health-care delivery effort [5]. Thus, in the present study utilizes the WHO drug use indicators as a preliminary tool for analyzing prescriptions written by physicians in outpatient clinics.

\section{METHODS}

\section{Study design}

An observational, cross-sectional descriptive study was carried out in various community pharmacies where the prescriptions received were analyzed for their quality. The study was carried out in the outpatient clinics in Aseer Central Hospital, which is a tertiary hospital equipped with 550 beds in Abha city, Saudi Arabia.

\section{Sample size and data collection}

A sample size of 250 handwritten outpatient prescriptions were computed and they were collected from the community pharmacies that reached from various clinical settings. The duration of this study was 2 months. The prescriptions were collected for a period of 5 weeks (April 26, 2017, to May 27, 2017) and then analyzed for the clerical and clinical errors.

The prescriptions were then assessed for errors using a checklist of errors adapted from the WHO recommendations for guide to good prescribing [6]. The prescriptions were considered as having errors if they have at least one of the following errors.

- Missing patient/physician information

- Generic/brand name of drugs

- Drugs without indications/drugs without drugs

- Wrong formulation;

- Improper or omitted route of administration;

- Improper or omitted frequency;

- Drug duplication;

- Potential drug/drug interaction

- Unauthorized drug;

- Incorrect treatment duration;

- Illegible order; and

- Missing or inaccurate patient height and/or weight [6].

Legibility was checked as follows [7]:

1. Legible can read the medication order without consulting other health-care professional or references.

2. Legible with effort can read the medication order after consulting with one or more health care professionals and/or references.

3. Illegible, cannot read the medication order, despite consultation with one or more health-care professionals and/or references [7]. 
Data analysis

A special data collection form is prepared and the prescription errors were transferred.

Data were entered and analyzed using the descriptive statistics and represented as percentages (\%).

\section{RESULTS}

\section{Demographic data}

During the study period, a total of 250 prescriptions, including in the checklist of the WHO guideline criteria the most common superscription errors are present in Table 1.

Date of prescription are not mention "absent" nearly 31\% were patient's name not included for $15 \%$, age $48 \%$, sex $46 \%$, weight absent for nearly $97 \%$, the allergy $96 \%$, and diagnosis are not included for $31 \%$.

\section{Drugs per prescription}

The number of drugs per prescription from 1 to 8 is shown numbers number 1 as minimum and number 8 as maximum number, the figure one nearly 65 (26\%), two 77 (31\%), three 51 (20\%), four 31 (12\%), five $13(5 \%)$, six 7 (3\%), seven $5(2 \%)$, and eight $1(0.4 \%)$ are shown in Fig. 1.

\section{Drug Duplication and omission errors}

Duplication of the drug is occurring $14(6 \%)$, drugs without indication 88 (35\%), indications without drugs $9(4 \%)$, usage of the drug for the indication supported by evidence 136 (54\%), and medication available in the formulary or essential drug list 246 (98\%) are shown in Table 2.

\section{Categories of drugs}

Categories of drugs prescribed are variation in a lot of categories, NSAIDs and analgesics 32 (13\%), antipyretics 104 (42\%), antibiotics $184(74 \%)$, antihistamines and cold preparations $6(2 \%)$, antacids and antiulcer 21 (8\%), antidiabetics 30 (12\%), corticosteroids 59 (24\%), hormones and oral contraceptives 7 (3\%), antidepressants/ antipsychotics/CNS activators 18 (7\%), antiepileptics 4 (2\%), cough suppressants and expectorants $3(1 \%)$, antispasmodics and antiemetics 7 (3\%), bronchodilators $14(6 \%)$, nasal decongestants 3 (1\%), topical skin preparations 35 (14\%), laxatives 4 (2\%), antihypertensives and other CVS agents 30 (12\%), antihyperlipidemic 7 (3\%), drugs for $\mathrm{BPH}$ $0(0 \%)$, vitamins, minerals, and nutritional supplements $11(4 \%)$, oral rehydration solutions 7 (3\%), eye/ear drops/ointments 94 (38\%), antifungal $5(2 \%)$, antiviral $6(2 \%)$, anticoagulation $18(7 \%)$, and the drugs cannot justify 17 (7\%) that are shown in Table 3.

\section{Drug-drug interaction}

Drug-drug interaction in the prescriptions between three degrees (minor - moderate-severe); whereas the minor is occurring $0(0 \%)$, moderate $18(7 \%)$, and major $1(0.04 \%)$ that are shown in Table 4.

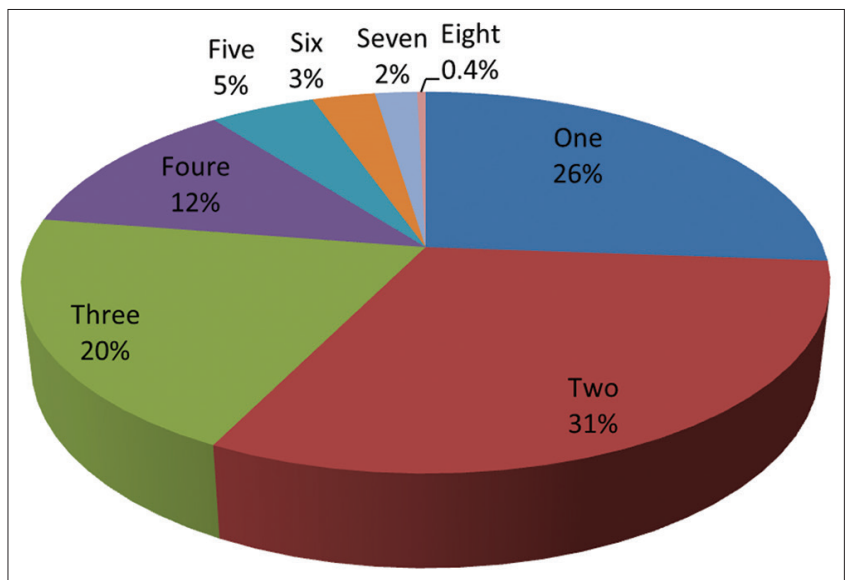

Fig. 1: Number of drugs per prescription
Mode of prescribing the product/drug is variation between three choices (generic-brand-mixed) names, the generic was mentioned 43 (17\%), brand was mentioned 127 (51\%), and mixed was presented nearly $80(32 \%)$ times (Table 5).

\section{Inscription errors}

Most common inscription errors are included in prescription, illegible prescription or bad handwriting $66(26 \%)$, omission or incomplete information on strength of medicine 140 (56\%), omission or incomplete information on dosage form 59 (24\%), omission or incomplete information on dose 35 (14\%), omission or incomplete information on frequency $18(7 \%)$, and omission or incomplete information on duration 47 (19\%) that are shown in Table 6.

\section{Prescriber's information errors}

Most common errors in prescriber's information such as prescriber's name were missed (19\%) and prescriber's signature missed (30\%) that are shown in Table 7 .

\section{DISCUSSION}

Medical prescription errors by health professionals cause a serious public health problem and these errors sometime become a threat to the patient's life. Many studies have reiterated that incomplete or omitted information in the prescriptions and poor handwriting leads to numerous errors $[8,9]$. In our present study, we analyzed the essential element of prescriptions such as legibility and completeness of handwritten prescription. It was suggested by Calligaris et al. that overall illegibility or incompleteness of more than $20 \%$ is unacceptably high [10].

In our study, we found the following superscription errors. The date of prescription, patients' name, age, sex, weight, allergies, and diagnosis was missing in 31\%, 15\%, 48\%, 46\%, 97\%, 96\%, and 31\% of the prescriptions, respectively. Similar results were found in a study conducted by Balbaid and Al-Dawood [11], which demonstrates an omission of a patient's name in $14.5 \%$ of the prescriptions. On the other hand, a large number of gender and age are missing in the prescriptions

Table 1: Most common superscription errors

\begin{tabular}{|c|c|c|c|}
\hline S. No. & Elements & Result & $\%$ of incidence \\
\hline \multirow[t]{2}{*}{1} & \multirow[t]{2}{*}{ Date of prescription } & Present & 69 \\
\hline & & Absent & 31 \\
\hline \multirow[t]{2}{*}{2} & \multirow[t]{2}{*}{ Patient's name } & Present & 85 \\
\hline & & Absent & 15 \\
\hline \multirow[t]{2}{*}{3} & \multirow[t]{2}{*}{ Age } & Present & 52 \\
\hline & & Absent & 48 \\
\hline \multirow[t]{2}{*}{4} & \multirow[t]{2}{*}{ Sex } & Present & 54 \\
\hline & & Absent & 46 \\
\hline \multirow[t]{2}{*}{5} & \multirow[t]{2}{*}{ Weight } & Present & 3 \\
\hline & & Absent & 97 \\
\hline \multirow[t]{2}{*}{6} & \multirow[t]{2}{*}{ Allergies } & Present & 4 \\
\hline & & Absent & 96 \\
\hline \multirow[t]{2}{*}{7} & \multirow[t]{2}{*}{ Diagnosis } & Present & 69 \\
\hline & & Absent & 31 \\
\hline
\end{tabular}

Table 2: Drug duplication and omission errors

\begin{tabular}{llll}
\hline S. No. & Error category & Frequency & \% of incidence \\
\hline 1 & Drug duplication & 14 & 6 \\
2 & Drugs without indication & 88 & 35 \\
3 & Indications without drugs & 9 & 4 \\
4 & $\begin{array}{l}\text { Is the usage of the drug for } \\
\text { the indication supported by }\end{array}$ & 136 & 54 \\
& $\begin{array}{l}\text { evidence? } \\
\text { Is the medication available }\end{array}$ & 246 & \\
5 & $\begin{array}{l}\text { in the formulary or essential } \\
\text { drug list? }\end{array}$ & \\
& & \\
\hline
\end{tabular}


Table 3: Categories of drugs prescribed

\begin{tabular}{|c|c|c|c|}
\hline S. No. & Category of drugs & Frequency & $\%$ of occurrence \\
\hline 1 & NSAIDs and analgesics & 32 & 13 \\
\hline 2 & Antipyretics & 104 & 42 \\
\hline 3 & Antibiotics & 184 & 74 \\
\hline 4 & Antihistamines and cold preparations & 6 & 2 \\
\hline 5 & Antacids and antiulcer & 21 & 8 \\
\hline 6 & Antidiabetics & 30 & 12 \\
\hline 7 & Corticosteroids & 59 & 24 \\
\hline 10 & Antidepressants/antipsychotics/CNS activators & 18 & 7 \\
\hline 11 & Antiepileptics & 4 & 2 \\
\hline 12 & Cough suppressants and expectorants & 3 & 1 \\
\hline 13 & Antispasmodics and antiemetics & 7 & 3 \\
\hline 14 & Bronchodilators & 14 & 6 \\
\hline 15 & Nasal decongestants & 3 & 1 \\
\hline 16 & Topical skin preparations & 35 & 14 \\
\hline 17 & Laxatives & 4 & 2 \\
\hline 19 & Antihyperlipidemics & 7 & 3 \\
\hline 20 & Drugs for $\mathrm{BPH}$ & 0 & 0 \\
\hline 21 & Vitamins, minerals, and nutritional supplements & 11 & 4 \\
\hline 22 & Oral rehydration solutions & 7 & 3 \\
\hline 23 & Eye/ear drops/ointments & 94 & 38 \\
\hline 24 & Antifungal & 5 & 2 \\
\hline 25 & Antiviral & 6 & 2 \\
\hline 26 & Anticoagulation & 18 & 7 \\
\hline 27 & Cannot justify & 17 & 7 \\
\hline
\end{tabular}

NSAIDs: Nonsteroidal anti-inflammatory drugs

Table 4: Drug-drug interaction

\begin{tabular}{llll}
\hline S. No. & Classification & Frequency & \% of incidence \\
\hline 1 & Minor & none & 0 \\
2 & Moderate & 18 & 7 \\
3 & Severe & 1 & 0.4 \\
\hline
\end{tabular}

Table 5: Mode of prescribing the product/drug

\begin{tabular}{llll}
\hline S. No. & Mode & Number of prescriptions & \% of incidence \\
\hline 1 & Generic & 43 & 17 \\
2 & Brand & 127 & 51 \\
3 & Mixed & 80 & 32 \\
\hline
\end{tabular}

and showed a higher percentage of the incompleteness of age when compared to the other studies conducted in other regions of Saudi Arabia [12,13].

The WHO recommends the presence of the age in the prescriptions especially for children and elderly [14]. This is extremely significant to have the right drug, right dose, and the right dosage form to the right aged person [14]. In addition, our findings showed nearly $31 \%$ of the prescriptions were not having a diagnosis which is in agreement with some similar studies, which also reported the missing of diagnosis in the prescription [11-13]. According to the hospital prescription regulations, it was recommended to include the diagnosis of the patient in the hospital prescription list. Therefore, our study results demonstrate to the hospital management to emphasize the necessity of writing clear and complete prescriptions to interpret correct patient information.

In the present study, only $17 \%$ of the medications were prescribed by generic name, $32 \%$ of prescriptions were written with both brand and generic names and $51 \%$ of medications were prescribed by their brand names. These results are in line with some similar studies conducted by Castilho et al. and Irshaid et al., 2005 which report nearly 34\% and $50.1 \%$ of the medications were written by brand names $[12,15]$.
According to the WHO [6], it is recommended to use the generic name for all medications prescribed by physicians. A study by Shrank et al. showed that prescribing the medicines by generic name not only saved money but also improved the likelihood of patients taking their medicines [16]. The use of generic names will enable the pharmacist to maintain a more limited stock of drugs and avoid the unnecessary expensive drugs for the patient. Therefore, the use of generic names, especially in emerging countries such as Saudi Arabia, could potentially reduce medication prices, as well as facilitate patient access and adherence to treatment.

The inscription errors committed in the prescriptions included in our study were worse than those reported previously. Balbaid and Al-Dawood [11] reported that the dose, frequency, and duration of medications were deficient in $7.6 \%, 6.9 \%$, and $10.2 \%$ of prescriptions, respectively. Bawazir [13] reported that the dose of the drug was missing in $4 \%$ of prescriptions. We found that more than half $(56 \%)$ of prescriptions did not include the strength of the medication, the dose units were not included in 14\%, and the dosage form of medications was not included in $24 \%$ of prescriptions. It sounds as if, these parameters are left to the pharmacist to decide upon and the implications for the duration of therapy will be dependent on the individual pharmacist. The strength of medication is particularly needed when the pharmaceutical product exists in more than one strength.

Illegible prescription is one of the factors, which can increase the risk for medication errors regardless of the accuracy, and completeness of the prescription [17]. Illegibility of physicians' handwritten prescription orders is a problem that has been mentioned in almost every publication related to prescribing errors [17]. The results of our study also corroborate with the study of Mendonca et al., where they found the illegibility rate as $26 \%$ out of 300 dental prescriptions [18].

Our finding is in contrast with what was found by Balbaid and AlDawood [11] who reported illegible handwriting in only $7.2 \%$ of prescriptions. The high percentage of poor handwriting we found could be due to the fact we considered the presence even of a single unclear word or a dose unit as poor handwriting for the whole prescription. Poor handwriting is a serious problem that might lead to dispensing the 
Table 6: Most common inscription errors

\begin{tabular}{|c|c|c|c|}
\hline S. No. & Error category & Frequency & $\%$ of incidence \\
\hline 1 & Illegible prescription or bad handwriting & 66 & 26 \\
\hline 2 & Omission or incomplete information on the strength of the medicine & 140 & 56 \\
\hline 3 & Omission or incomplete information on dosage form & 59 & 24 \\
\hline 4 & Omission or incomplete information on dose & 35 & 14 \\
\hline 5 & Omission or incomplete information on the frequency & 18 & 7 \\
\hline 6 & Omission or incomplete information on duration & 47 & 19 \\
\hline
\end{tabular}

Table 7: Most common errors in prescriber's information

\begin{tabular}{llll}
\hline S. No. & Elements & Result & \% of incidence \\
\hline 1 & Prescriber's Name & Present & 81 \\
& & Absent & 19 \\
2 & Prescriber's Signature & Present & 70 \\
& & Absent & 30 \\
\hline
\end{tabular}

wrong medication to the patient with serious or even fatal results [18]. Therefore, the study results indicate the physicians and other health professionals as their responsibility for clarity, accuracy, and precision of handwriting prescriptions.

\section{CONCLUSION}

This study is a small attempt to represent handwritten outpatient prescription errors in Aseer region, Kingdom of Saudi Arabia. In our study, the prescriptions we reviewed suffered from serious deficiencies and were not properly written, which indicates poor compliance of the prescribers to follow the national guidelines/WHO guidelines of prescribing. We found in this research that there is a deficiency in filling the patient-related information, prescriber related information, drug-related information, and legibility. Prescribing errors should be considered as a potential area for improvement in the medication management process and patient safety. Using a computer-aided prescribing system in the outpatient-clinics setting with must fill options (including full patient information, diagnosis, and name of the prescribing doctor) will help to decrease the possibility of medication errors.

\section{CONFLICTS OF INTEREST}

The author declares that they have no conflicts of interest.

\section{ACKNOWLEDGMENTS}

The author would like to thank King Khalid University for their administrative support and Aseer Central Hospital to allow us to perform the research.

\section{REFERENCES}

1. Hassan NB, Ismail HC, Naing L, Conroy RM, Rahman AR. Development and validation of a new prescription quality index. Br J Clin Pharmacol 2010;70:500-13.

2. Varghese NJ, Ramanarayanan V, Janakiram C, Joseph J. Assessment of quality of prescription writing among dental and medical students and practitioners in Kerala. J Nat Sci Biol Med 2018;9:27-33.
3. Suthar JV, Patel VJ. Assessment of quality of prescribing in patients of hypertension at primary and secondary health care facilities using the prescription quality index (PQI) tool. Indian J Pharmacol 2014;46:480-4.

4. Dyasanoor S, Urooge A. Insight into quality of prescription writing an instituitional study. J Clin Diagn Res 2016;10:ZC61-4.

5. Rastogi S. Looking at prescription quality in ayurveda: Developing, validating and pilot testing a prescription quality index for ayurveda. J Ayurveda Integr Med 2017;10:12-7.

6. De Vries TP, Henning RH, Hogerzeil HV, Fresle DA. A Practical Manual. Geneva: World Health Organization Action Programme on Essential Drugs; 1994. Guide to Good Prescribing. WHO/DAP/94.11. Available from: http://www.apps.who.int/medicinedocs/pdf/ whozip23e/whozip23e.pdf.

7. Winslow EH, Nestor VA, Davidoff SK, Thompson PG, Borum JC. Legibility and completeness of physicians' handwritten medication orders. Heart Lung 1997;26:158-64.

8. Brennan TA, Leape LL, Laird NM, Hebert L, Localio AR, Lawthers AG, et al. Incidence of adverse events and negligence in hospitalized patients. Results of the Harvard medical practice study I. N Engl J Med 1991;324:370-6

9. Barker KN, Flynn EA, Pepper GA, Bates DW, Mikeal RL. Medication errors observed in 36 health care facilities. Arch Intern Med 2002; 162:1897-903.

10. Calligaris L, Panzera A, Arnoldo L, Londero C, Quattrin R, Troncon MG, et al. Errors and omissions in hospital prescriptions: A survey of prescription writing in a hospital. BMC Clin Pharmacol 2009;9:9.

11. Balbaid OM, Al-Dawood KM. Assessment of physician's prescribing practices at ministry of health hospitals in Jeddah city Saudi Arabia. Saudi Med J 1998;19:28-31

12. Irshaid YM, Al Homrany M, Hamdi AA, Adjepon-Yamoah KK, Mahfouz AA. Compliance with good practice in prescription writing at outpatient clinics in Saudi Arabia. East Mediterr Health J 2005;11:922-8.

13. Bawazir SA. Prescribing patterns of ambulatory care physicians in Saudi Arabia. Ann Saudi Med 1993;13:172-7

14. Maxwell JC. Trends in the Abuse of Prescription Drugs. Gulf Goast ATTC Austin Treatment; 2006.

15. Castilho LS, Paixão HH, Perini E. Prescription of drugs of systemic use by dentists. Rev Saude Publica 1999;33:287-94.

16. Shrank WH, Hoang T, Ettner SL, Glassman PA, Nair K, DeLapp D, et al. The implications of choice: Prescribing generic or preferred pharmaceuticals improves medication adherence for chronic conditions. Arch Intern Med 2006;166:332-7.

17. Mendonça JM, Lyra DP Jr., Rabelo JS, Siqueira JS, Balisa-Rocha BJ, Gimenes FR, et al. Analysis and detection of dental prescribing errors at primary health care units in Brazil. Pharm World Sci 2010;32:30-5.

18. Charatan F. Family compensated for death after illegible prescription. BMJ 1999;319:1456. 